\title{
(In) vestindo camisas de futebol: moda esportiva e agência na produção das emoções torcedoras
}

Investing/Wearing Football jerseys: sportswear and agency in the production of fan's emotions 
Luiz Henrique de Toledo ${ }^{1}$

ORCID: https://orcid.org/0000-0002-5354-5923

[resumo] Camisas de futebol apontam para um duplo vínculo de uma experiência emocional, que tensiona a relação entre o indivíduo e o coletivo. A moda esportiva com seus ciclos, marcas e indumentárias aparece não somente como dispositivo estético e protético assentado nos valores do consumismo, mas também pode ser concebida como instância agentiva na fabricação da pessoa do torcedor. Este artigo procura articular moda e futebol de uma perspectiva antropológica, que trata corpo e suas projeções (corporalidades) como fundamentos simbólicos de comunicação e produção de relações, no caso, relações entre a cultura material expressa pela moda e o multiverso da sociabilidade torcedora a partir de uma modalidade esportiva, o futebol.

[palavras-chave] Moda esportiva. Corporalidade. Torcedores. Agência. Antropologia das práticas esportivas.

[abstract] Soccer jerseys point out to a double bond of an emotional experience that tighten the relationship between the individual and the collective. Sports fashion - with its cycles, brands and clothes - appears not only as an aesthetic and prosthetic device based on the values of consumerism, but it can also be conceived as an active instance in the manufacture of the fan figure. This article seeks to articulate fashion and football from an anthropological perspective, which treats the body and its projections (corporealities) as symbolic foundations of communication and relationship production, i.e., connections between the material culture expressed by fashion and the multiverse of fan sociability of a sports modality, soccer.

[keywords] Sports fashion. Corporeality. Fans. Agency. Sports anthropology .

Recebido em: 15-06-2019

Aprovado em: 26-10-2019

\footnotetext{
${ }^{1}$ Doutor em Antropologia Social pela Universidade de São Paulo (USP). Professor-pesquisador do Programa de Pós-Graduação em Antropologia Social (PPGAS) da Universidade Federal de São Carlos (UFSCar). Coordenador do Laboratório de Estudos de Práticas Lúdicas e Sociabilidade (LELuS). Autor de Lógicas no futebol (Hucitec-Fapesp, 2002) e Remexer anotações: o trabalho de um arguidor antropólogo (Edufscar, 2019). kikeppgas@gmail.com. http://buscatextual.cnpq.br/buscatextual/visualizacv .do?id=K4792025T7.
} 


\title{
Fashioned soccer?
}

O fenômeno do futebol, quando aportou no Brasil, na virada do século XIX para o XX, foi considerado por muitos intelectuais e seus detratores como uma moda ou um modismo ${ }^{2}$, ponto de vista que banalizava a própria noção de moda como algo instrumental, passageiro, fugaz e impertinente. Como se viu no desenrolar dos últimos séculos, nem o mundo da moda nem o do futebol saíram de cena com o avançar da modernidade, que se consolidou a partir dos grandes centros urbanos desde a segunda metade do século XIX.

Em meio ao ferrenho embate econômico que se acirrava naquele século entre pragmatismos liberais e materialismo histórico, pensadores como Thorstein Veblen, precocemente, se comparado ao desenvolvimento das Ciências Sociais, já desfiava o tecido e as camadas da vida social para incluir em seu horizonte de reflexão fenômenos como a moda, mostrando sua importância para compreender a modernidade que despontava:

\begin{abstract}
E o valor comercial dos bens usados no vestuário em qualquer comunidade moderna em grande parte se compõe da moda corrente e do prestígio que se atribui a esses bens, mais que do serviço mecânico que o vestido presta à pessoa que o usa. A necessidade de vestuário é, pois, uma necessidade "mais alta", ou seja, espiritual. (VEBLEN, 1974, p. 362) ${ }^{3}$
\end{abstract}

Já os movimentos não naturais e frenéticos impingidos aos corpos, orientados pelos valores caros ao modo de vida individualista burguês ${ }^{4}$, tais como meritocracia, competitividade, superação, autodisciplina, também produziram uma nova beleza corporal cada vez

\footnotetext{
2 Visão partilhada por muitos escritores, entre eles o mais engajado em denunciar o estrangeirismo da nova prática, Lima Barreto (RODRIGUES FILHO, 1995; TOLEDO, 1996). Nas décadas subsequentes, a literatura, cada vez mais, abraçaria o futebol como mote para suas fugas estéticas. Em um sentido um tanto inverso, vale a consulta à coletânea Entre as quatro linhas: contos sobre futebol, especificamente Levi (2013), que traz o tema da camisa na trama intrincada das personagens, mas, sobretudo, colocando-se como protagonista em Um dia, uma camisa.

3 Todavia, Marshal Berman problematiza o caráter determinista e economicista presente no materialismo histórico em Marx. Se as vulgatas marxistas centraram no polo da modernização, visibilizando as esferas econômica e política, Marx, para Berman, apontava também para os aspectos da arte, da cultura e da sensibilidade presentes no âmago da perspectiva modernista. Portanto, reivindicando um Marx modernista, escreve: "Quanto mais perto chegamos do que Marx, de fato, disse, menos sentido faz esse dualismo [modernização e modernismo]. Tomemos uma imagem como esta: 'Tudo que é sólido desmancha no ar’. A ambição cósmica e a grandeza visionária da imagem, sua força altamente concentrada e dramática, seus subtons vagamente apocalípticos, a ambiguidade de seu ponto de vista - o calor que destrói é também energia superabundante, um transbordamento de vida -, todas essas qualidades são, em princípio, traços característicos da imaginação modernista” (BERMAN, 1986, p. 88).

${ }^{4}$ Trata-se daquilo que Waizbort (2013), ao esmiuçar o pensamento de um autor crucial para se compreender a modernidade, Georg Simmel, nomeará de "papel duplo do dinheiro": "Apesar do dinheiro ser objetivo e impessoal e promover a objetividade e a impessoalidade, ele possui também uma relação estreita com a individualidade com o 'princípio do individualismo'” (WAIZBORT, 2013, p. 173).
} 
mais desejada e glamourosa, expressa com o advento e a popularização dos esportes ditos modernos. E emulando a atividade física despertada nos milhares de recém-convertidos torcedores, que viram no futebol a ampliação do espaço lúdico e da sociabilidade, consumindo-o não apenas com os pés, mas também com os olhos, o futebol soube traduzir os desígnios desses novos tempos, tempos do consumo ubíquo centrados em uma nova corporalidade e em uma gestão dos sentidos. Corpos atléticos extravasariam os limites das práticas esportivas ganhando a moda da rua, vestindo (e ao mesmo tempo desvestindo) gerações que passam a habilitar um conjunto de novas expressões estéticas. Correr, saltar, servir-se dos corpos em movimentos frenéticos respondiam aos desígnios da vida nas cidades e metrópoles nascentes (SEVCENKO, 1992).

É notável que a moda, que se tornou atividade economicamente orientada de julgamento estético de corpos belos e bem trajados, de maneira cada vez mais evidente, no século XIX, tenha se sensibilizado muito antes do ambiente do futebol no sentido de relativizar a condição masculinizante imposta, de modo geral, às práticas esportivas coletivas. Nos aglomerados das arquibancadas, ainda nos primeiros decênios do século XX, mulheres faziam-se muito presentes e podiam torcer e exibir seus cuidados estéticos em um ambiente que reinava o combate corporal figurado entre homens.

Na verdade, muitas já se insinuavam no manejo do jogo, apesar de o futebol praticado por mulheres ter sido cerceado pelos discursos estatais e cientificistas naturalizantes ${ }^{5}$, que buscavam frear e se impor como obstáculos às possibilidades da prática, condição que perdurou por décadas a despeito de muitas investidas contrárias, sejam insurgentes ou no sentido da inserção institucional nesse campo. Tomando São Paulo como cidade moderna ainda na virada do século XIX para o XX, a própria rua, passarela intuitiva que certamente serviria de modelo para se chegar às formas estilizadas que hoje se conhece nos rituais da moda, era tomada como lugar dos excessos e perigos à exposição e à presença feminina, tal como nos relata Frehse sobre a relação entre rua e moda no alvorecer da modernidade paulistana. Comparando a reclusão das elites com o perambular das classes populares, escreve:

Já quando são outros os pedestres e trajes, são outras as ruas. Paes de Barros não se furta a tematizar os trajes dos "negros" - além da "calça e camisa de algodão" e dos "pés nus", a "cabeça descoberta" - ou a "minguada" carga do "caipira", nas estradas e campos. (FREHSE, 2011, p. 153)

\footnotetext{
As tentativas de interdição do futebol às mulheres inserem-se em um amplo debate sobre a natureza e o destino social do corpo feminino nos séculos XIX e XX. Como aponta Rohden, em um trabalho sobre as concepções de saúde pública visando às mulheres: "Os médicos se apresentavam também como legisladores sociais, bem preparados pelo conhecimento científico, e capazes de prescrever as normas mais adequadas no que se refere ao comportamento sexual e reprodutivo dos indivíduos [...] muitas vezes categorias que tiveram origem na medicina vão passar a ser recorrentes no discurso jurídico e policial" (ROHDEN, 2003, p. 19).
} 
Mas vestir-se e desvestir-se fez parte da dialética que alcançou tanto as ruas quanto a moda e os esportes. E, para além de constituírem fenômenos solidários entre si por intermédio de causas e efeitos históricos, portanto passíveis de reconstituição processual e sociológica ${ }^{6}$, ocultar ou revelar corpos cumpre desígnios antropológicos que estão para além mesmo desse mundo ocidental e suas narrativas, definindo fronteiras (fixas ou reflexivas) muito mais espraiadas que sempre posicionaram as relações entre o humano e a natureza dentro de metafísicas que versam sobre existências e moralidades a respeito dos usos dos corpos.

Pode-se pensar também que o encontro entre esportes e moda trouxe consigo o esgarçamento dos sexos, sobretudo dos gêneros, e uma maior relativização crítica da condição masculinizante que tanto se impôs às modalidades esportivas, como o futebol. A aproximação entre o universo predominantemente feminilizante da moda, que abriga homens, mulheres e tantos outros gêneros, do universo excessivamente masculinizante dos esportes foi, sem dúvida, uma marca dos novos tempos. A moda, assim como o futebol moderno, ganhou substância política, além de estética e consumista, e passou a flertar outros caminhos inusitados pela universalização dos direitos para todos, dos usos dos corpos nos espaços públicos e o vivenciar e reivindicar outras subjetividades.

Hoje é comum jogadores, sobretudo aqueles que alcançam o estrelato esportivo, participarem ativamente do mundo da moda como modelos, empresários, patrocinadores a produzir novas tendências estéticas. Caem as máscaras de uma masculinidade meramente viril e reativa, tão emulada pelos esportes por décadas de recalque de gênero e de classe.

E a moda catalisou o fluxo entre os gramados e a rua e, em uma retroalimentação, levou costumes do campo de jogo para os espaços públicos, para homens e mulheres comuns que vestem a moda esportiva no seu dia a dia, deslocando o campo esportivo e atlético para novas sensibilidades e experimentações, transitando das passarelas não somente os trajes, os estilos e as tendências, mas todo um cultivar de novos hábitos, de viver e de jogar. A moda hoje também dita a conduta de jogadores, torcedores, técnicos, dirigentes e traduz, nesses novos corpos, outros desígnios da condição cidadã e esportiva.

Portanto, é provável que o futebol não saia de moda porque, ao menos até este momento histórico, aprendeu a ficar atento às transformações de toda ordem extracampo, e ainda que cada vez mais esteja orientado pela lucratividade e pelos poderes assimetricamente investidos, também diz muito a respeito dos hábitos e costumes insurgentes que norteiam os mundos orientados pelos experimentalismos; aliás, característica essencial do mundo da moda que investe continuadamente em ciclos estéticos e comportamentos estilizados.

\footnotetext{
${ }^{6}$ Há toda uma produção relacionada à perspectiva sociológica (e outras) sobre moda não contemplada nos limites deste artigo. Para uma visão abrangente sobre essa literatura acadêmica, que trata da produção intelectual sobre o fenômeno da moda, recomendo Cidreira (2005). Da perspectiva antropológica, sugiro Mizrahi (2019).
} 


\section{Desvestindo um problema}

Camisas de futebol são mais do que meros adornos ou fardamentos indicativos da prática distintiva do futebol no reino dos esportes. ${ }^{7}$ Revelam, obviamente, algo para além da condição de suporte para a exposição dos signos, escudos, cores, marcas e logotipos de patrocinadores. Obviamente, também não são meras indumentárias no sentido de aderirem aos corpos de maneira inerte, vestindo jogadores profissionais, amadores e torcedores, e, é nesse sentido, que podem ser analisadas não como mais um produto tardiamente capturado pela indústria da moda. Ao contrário, tais vestimentas são historicamente solidárias à moda, tal como aludi no tópico acima.

Permitam-me seguir com um relato mais pessoalizado e um tanto errático a respeito da minha participação em um projeto de uma exposição ocorrida entre 2013 e 2014, que fez parte dos inúmeros eventos que pipocaram na produção do clima que tentou, e como se sabe hoje em grande medida fracassou, envolver e engajar os coletivos de torcedores brasileiros na ocasião da Copa do Mundo de futebol de homens, realizada no Brasil, em $2014^{8}$.

Entre tantos eventos oficiais impulsionados em torno daquele megaevento ${ }^{9}$, essa modesta, confessadamente descontínua e pouco entusiasmada participação que tive nos bastidores da produção de Brasil, um país, um mundo, exposição sobre o futebol brasileiro idealizada por uma empresa privada ${ }^{10}$ em parceria com setores do Estado, permitiu casualmente tomar contato com aquilo que, de fato, será o tema da reflexão que segue, ou seja, pensar a respeito dessa icônica indumentária esportiva, que são as camisas de futebol.

A perspectiva oferecida aqui é tomar esses artefatos esportivos como produtos e produtores de relações agentivas entre torcedores, ou seja, extrair dessa experiência algo para além da noção naturalizante de que camisas servem para vestir (no sentido de cobrir) cor-

\footnotetext{
Para uma análise sobre clubismo e o papel das camisas de futebol na fabricação da pessoa torcedora, ver Toledo (2014).

8 Já existe uma bibliografia diversa e crítica sobre os desdobramentos sociopolíticos em torno da organização desse megaevento e seus legados dentro daquilo que foi formatado pela expressão "década esportiva", tal como proposta na coletânea Entre jogos e copas (SPAGGIARI; MACHADO e GIGLIO, 2016). Desde 2013, acirraram os movimentos contrários aos gastos públicos com a copa, que vinham na esteira de uma crítica mais difusa e generalizada à conjuntura política. Documentos tomados como autoritários, como a Lei Geral da Copa, emitidos pela FIFA com anuência do governo, também foram alvo de críticas em relação aos supostos legados culturais e materiais que a copa poderia trazer ao país. Não é minha intenção discutir as inúmeras visões produzidas pelas pesquisas no campo dos cientistas sociais a respeito desses desdobramentos. Deixo na bibliografia algumas sugestões, tais como os textos de Martin Curi sobre as novas arenas e o de Sergio Giglio, sobre o tema do poder hegemônico institucional da FIFA, na já citada coletânea, bem como, por exemplo, o Dossiê Megaeventos Esportivos produzido para o número 40 da revista Horizontes Antropológicos, ou ainda os textos reunidos em uma coletânea interdisciplinar sobre futebol, na Revista USP, número 99. Há, no entanto, muitas outras contribuições importantes que um levantamento bibliográfico mais cuidadoso certamente irá visibilizar.

9 Para uma conceituação de megaevento consultar, por exemplo, Mascarenhas (2009).

${ }^{10} \mathrm{~A}$ Rainmaker Projetos e Produções Ltda., que atua na área curatorial de exposições artísticas e eventos culturais.
} 
pos, sejam corpos de atletas ou de torcedores. Ou ainda que camisas esportivas servem tão somente aos propósitos da identificação entre indivíduo e algum coletivo torcedor.

Sigo aqui, obliquamente, as sugestões de autores, como Alfred Gell, para quem em alguns contextos, notadamente etnológicos, mas creio que possam ser generalizados quando pensamos em moda esportiva, arte e artefato, não são tomados como fatores antitéticos, tal como pode ser exemplificado na discussão que Lagrou (2007) elabora sobre arte em um contexto amazônico, entre os Kaxinawa:

Gell mostra como instrumentalidade e arte não necessariamente precisam ser mutuamente exclusivas. [E segue:] Gell supera, dessa forma, a clássica oposição entre artefato e arte, introduzindo agência e eficácia onde a definição clássica só permite contemplação. (LAGROU, 2007, p. 44)

Nesse caso, expandindo as considerações acima, quero enfatizar a perspectiva de que vestir implica um (in)vestir para além do (en)cobrir os corpos, pois usar uma camisa esportiva pode ser concebido no acumular intenções, gestualidades, maneirismos e relações, expandindo tanto a ideia de vestir quanto a de desvestir. Investir, portanto, pode revelar menos um ponto de vista identitarista curto-circuitado na produção de solidariedades (entre torcedores, jogadores, um povo etc.) na medida em que abre espaço para se pensar o uso dessas camisas como espécie de encontro com o outro ou busca do ou contra outros.

Nessa direção argumentativa, torcer seria um investir na pessoa torcedora, sede tanto do individualismo quanto das projeções relacionais que o apanham na condição de indivíduo. Dessa forma, a moda se revelaria com um duplo vínculo entre o social e o subjetivo, ou seja, como ação do vestir, mas também propriedade material simbólica de induzir relações.

Se o indivíduo, ao usar suas camisas clubísticas de preferência, investe na estilização de um eu torcedor consumerista para ficar dentro da moda esportiva, ao mesmo tempo que entra em consonância com os gostos e as preferências de outros tomados por iguais (da mesma torcida), expande tanto essas experiências subjetivas quanto coletivas na medida em que o uso dessas camisas translada e subverte os espaços dessas duas experiências marcadas, seja o consumo individualista, seja a adesão coletiva clubística, multiplicando e metaforizando outros espaços da sociabilidade para muito além do futebol. A camisa deixa de ser mera indumentária para se agregar como metáfora na produção da pessoa, modulando e produzindo ambiguidades entre os usos estritamente individualizantes e ou esportivamente coletivizantes ${ }^{11}$.

\footnotetext{
${ }^{11}$ Para um caso de relativização clubística, ou seja, aquele torcedor que, como se diz, vira casaca e sai vestindo e desvestindo camisas de vários clubes, ver Toledo (2014).
} 
Portanto, as camisas, essa segunda pele como costumeiramente se diz, operam como força agentiva a produzir interatividades entre as fronteiras que divisam o individual e o social, o interno e o externo, o time preferido e os outros, colocando o indivíduo em outros fluxos de relações que não remetem estritamente à sua posse como condição consumerista ou puramente esportiva de adesão clubística ao jogo.

Os inúmeros casos em que as camisas de futebol foram e são usadas metaforicamente e apropriadas em movimentos de caráter político é um exemplo notório e reiterativo mundo afora dessa expansão dos significados do (in)vestir uma camisa esportiva. Particularmente, em períodos mais recentes da história brasileira, que a Historiografia define por período da redemocratização, inaugurado com a derrocada do regime militar, camisas de futebol (não somente a da seleção brasileira) serviram para (in)vestir cidadãos oriundos tanto do espectro político mais à esquerda, tal como se notabilizou no movimento chamado Diretas Já (1984), cujos desdobramentos foi o retorno do país à rotina das eleições para presidente da República, quanto posicionamentos ideológicos mais à direita, tal como foi o caso dos setores que protagonizaram nas ruas as insatisfações com o governo de centro-esquerda de Dilma Rousseff e sua derrocada formal com o processo parlamentar do impeachment, em 2016.

De todo modo, objetos de intensa especulação sociológica e estética, camisas esportivas se espalham pelo campo ou pelo sistema da moda como artefatos que paulatinamente acumulam valores tangíveis e intangíveis relacionados ao glamour e ao luxo extrínsecos ao campo esportivo, complexificando imagens que sustentaram por muito tempo um suposto caráter espontâneo e popular de se jogar futebol. Ao menos aquelas que compõem o mercado de bens disponibilizados oficialmente por clubes, federações, confederações e empresas esportivas multinacionais, camisas de clubes, sobretudo as que vestem os mais prestigiados times em termos de número de torcedores, valor da marca em mercados de capitais e patrimônio material e simbólico capitalizados, tornaram-se produtos cada vez mais caros e inacessíveis ao consumo das classes populares. Todavia, tal valorização não inibiu que torcedores oriundos de frações das classes menos abastadas experienciassem as extensões um tanto mais insurgentes da moda esportiva, estimulada, em boa parte, por mercados paralelos que o senso comum define por pirataria, movimentando a reprodução desses artefatos para o consumo torcedor em escalas mais fracionadas e locais, suprindo demandas e paixões clubísticas país afora.

Mas, antes de retomar alguns desses argumentos, voltemos ao contexto da exposição Brasil, um país, um mundo, que abrigou algumas sessões temáticas, inclusive a moda futebolística, cujo texto que consta do catálogo da exposição foi assinado pela conhecida editora de moda Lilian Pacce ${ }^{12}$. Segundo esboços iniciais do projeto que tive acesso na ocasião que

\footnotetext{
${ }^{12}$ Ainda na copa de 2014, o seu blog faria outra menção ao futebol: "A Arezzo armou evento na loja da 0scar Freire, em SP, pra lançar a exposição Camisa 10: moda \& futebol, que traz a camisa 10 brasileira reinventada por 11 estilistas nacionais. Em clima de Copa do Mundo, Deborah Secco apareceu por lá e o Blog LP conversou com ela sobre o mundial, afinal a atriz foi casada com o ex-jogador Roger Flores durante 4 anos". Disponível em: https://www.lilianpacce.com.br/moda/deborah-secco-expectativas-copa/. Acesso em: 8 jun. 2019. Quatro anos mais tarde, a mesma editora de moda voltou a mencionar a relação entre futebol e moda no ano da copa ocorrida na Rússia, em 2018, a respeito da exposição Fanatics Fellings, "feira de moda masculina", ocorrida em Florença, entre 13 de junho e 22 de julho daquele ano. Disponível em: https://mw. lilianpacce.com.br/e-mais/fanatic-feelings-expo-que-fala-de-futebol-e-moda/. Acesso em: 7 jun. 2019.
} 
me chegou o convite para fazer parte da curadoria ${ }^{13}$, pode-se ler na conceituação geral da proposta:

\begin{abstract}
Aproveitar os anos e meses que antecedem o Mundial de 2014 - momento em que os olhos de todo o planeta estarão voltados para o Brasil - para renovar e atualizar a imagem do país, mostrando ao mundo nossa evolução política, econômica e industrial, nossa relevância cada vez maior como potência global, a beleza única de nossas cidades e do nosso território, e a singularidade do nosso povo. ${ }^{14}$
\end{abstract}

Seria como se a camisa da seleção brasileira naquele momento de efeméride esportiva pudesse (in)vestir e reinvestir no país os signos de uma modernidade que se colocava à prova no contexto mundial.

Se as melhores intenções culturalistas de mostrar um país renovado ao mundo fracassaram, inclusive dentro de campo com a retumbante derrota para o selecionado time alemão por 7 a 1 nas semifinais da competição ${ }^{15}$, entre os contextos fragmentários que envolveram minha modesta participação crítica desde a concepção original da exposição, recupero aqui o dia em que tive a oportunidade de conhecer o acervo particular de um conhecido colecionador paulistano ${ }^{16}$ de indumentárias esportivas que compôs a memorabília de parte da exposição. Visitando sua reserva técnica, impressionou-me a quantidade e a qualidade da coleção de camisas de jogadores nacionais e internacionais. No pouco tempo que observei a coleção, pude constatar que se trata de um mercado que fica entre o mundo da moda propriamente dita e o da arte.

Ali, entre inúmeras camisas e outros objetos (uniformes de treino, chuteiras, bolas) que contam histórias de tantos jogadores e times mundialmente populares e de grande expressão, ele me narrou que a venda de uma determinada camisa de um conhecidíssimo jogador da seleção inglesa, camisa que estava sendo procurada pela imprensa esportiva daquele país, rendeu-lhe a compra de um apartamento e custeio de toda a sua festa de casamento. A aquisição de itens para a sua imponente coleção de camisas (pude ver ao menos umas dez utilizadas por Pelé) obedece a um critério específico, ou seja, o de que toda camisa deve ter sido usada pelo menos uma vez, seja em um jogo oficial competitivo, seja amistoso. 0 uso, o contato corporal e o anímico com os movimentos corporais presentes em um jogo, enfim,

\footnotetext{
${ }^{13}$ Minha participação aparece na ficha técnica do catálogo como curador associado e no índice de textos produzidos para a exposição como autor de Guerra e paz e Sagrado futebol.

${ }^{14} \mathrm{Na}$ apresentação um tanto ufanista do projeto, podia-se ler: "Agora é a hora de mostrar para nosso povo, e também para o mundo, como somos um país em crescimento, um país vivo, cheio de energia, expressivo por economia em desenvolvimento e com força política, fazendo assim o Brasil se superar a cada dia" (Projeto Brasil, um país, um mundo, 2013. Mimeografado).

${ }^{15}$ Para uma análise sobre esse evento, sugiro o artigo De olhos bem abertos ou o que se viu e ouviu na Copa do Mundo de 2014: ensaio de antropologia das emoções esportivas (TOLED0, 2016).

${ }^{16}$ Ainda que se possa chegar ao citado colecionador, não mencionarei o nome dele neste artigo.
} 
essa relação intrínseca entre materialidade e espiritualidade definem seus critérios estéticos de aquisição desses artefatos.

Portanto, somente ingressam na coleção camisas dotadas de intencionalidade, fator crucial para que tanto a arte quanto a moda estabeleçam os critérios de julgamento desses itens colecionáveis. Caberia especular se camisas que participaram de eventos de moda, vestidas por jogadores famosos ou outras personalidades no jogo imitativo das passarelas, poderiam ampliar esses critérios de pertença a esse universo colecionável.

\section{Camisa tem "alma"}

É preciso dizer que pretendo manter a argumentação sobre camisas que possuem agência mais afastada das explicações instrumentais que preconizam a normatividade e a necessidade de se estar uniformizado para se praticar um esporte. Mas também dizer algo diverso ou algo a mais a respeito da perspectiva simbólica presente no jargão antropológico de que o uso de camisas esportivas interpolam simbolicamente indumentárias e corpos em um movimento que se poderia definir por representação, quer dizer, que camisas servem, em última análise, como representação (cultura material) de algo maior ou exterior aos próprios corpos que as vestem e aí tal associação ou moda representaria algum coletivo que identificamos classificatoriamente por um time, um time representando uma cidade, ou um time representando todo um país ou um continente.

Embora a própria moda também estabeleça o seu sistema classificatório a partir de regionalismos e perspectivas culturalistas, evidenciando uma moda francesa, outra italiana e assim por diante, é preciso atentar para a moda como espaço de fluxos metafóricos em que prevalecem mais as relações do que as identidades estanques, daí seu ciclo frenético de eventos que fagocitam e fazem migrar daqui para ali tendências, gostos, juízos estéticos, objetos e pessoas, assim como no futebol se estabelece a tensão entre identidades coletivas (futebol brasileiro, futebol argentino) e estilos mais pessoalizados que rompem com essas barreiras impostas por ilusões identitárias ${ }^{17}$.

Porém a presença de uniformes está amparada na clarividente normatização que fixou o uso de camisas para que a apreensão visual de uma disputa esportiva pudesse ocorrer. E quem já experienciou a sociabilidade em jogos lúdicos, onde a presença de camisas não se faz obrigatória, passou pela sensação (não necessariamente ruim) de mistura e confusão que a ausência ou a falta de algum uniforme suscita quando a bola rola em meio àqueles praticantes indistintos, que, em movimento, tornam a discriminação dos times um exercício difícil para quem apenas assiste. Cito essa banalidade porque a obrigatoriedade do uso de camisas consta das regras do futebol, especificamente na regra de número 4 entre as 17 que

\footnotetext{
${ }^{17}$ Assumo aqui a ideia de ilusão não como alienação ou erro, mas como motivação simbólica na produção de relações. Neste sentido, ilusão seria uma invenção e, assim como inventamos tecnologia, máquinas que amparam nossa vida, inventamos ideias, conceitos e relações, quer dizer, estabelecemos no e com o mundo social relações de ilusão produtiva.
} 
formam o conjunto de preceitos normativos que organizam a prática universal desse esporte. Ali, na regra intitulada Equipamentos dos jogadores, pode-se ler, logo em seu primeiro parágrafo, que "o equipamento básico obrigatório de um jogador consistirá de um agasalho ou camiseta, calção, meias, caneleiras e calçado" (FRANCISCON, 1996, p. 35). Não deixa de ser curioso que não há necessariamente a obrigatoriedade do uso das camisas, podendo o time substituí-las por "agasalhos".

Em relação a essa proximidade entre camisas esportivas e instrumentos ou equipamentos esportivos, extrapolo os argumentos produtivistas de autores como Gumbrecht ao abordar o caráter protético que tais instrumentos ganham em competições esportivas, o que, na minha visão, também não valeriam nessa medida para pensar o uso das camisas no sentido que o autor quer oferecer para outros objetos que fazem parte do universo técnico presente nos esportes.

Pensando não exatamente na indumentária corporal, como as camisas, e citando instrumentos muito determinantes na caracterização e no desempenho em modalidades que extrapolam em muito os usos do corpo, dirá que tais instrumentos

[...] tornam possível superar os limites de um desempenho exclusivamente humano ao, por exemplo, multiplicar a velocidade máxima à qual um corpo pode se mover no espaço [ou ainda enfatizar] [...] a capacidade do ser humano de adaptar seu corpo à forma, aos movimentos ou ao funcionamento do instrumento. (GUMBRECHT, 2005, p. 124)

Seguindo na mesma página, o autor arremata seu argumento utilizando seus exemplos vindos do automobilismo e da equitação: "Quanto mais um atleta consegue adaptar seu corpo com perfeição à forma e aos movimentos de um cavalo ou de um carro, melhor ele os controla, e mais potencializa a eficácia de seu corpo" (GUMBRECHT, 2005, p. 124).

Por extensão, parece-me que tal argumentação, que restringe o aumento da eficácia e o estado anímico da pessoa do atleta aos instrumentos tecnológicos em detrimento de outros, não citar, por exemplo, as roupas como aceleradoras simbólicas dos desempenhos faz com que essa interpretação sobre o uso das camisas fique ainda mais presa ao seu caráter meramente instrumental e prático. Como instrumentos ou coisas, as camisas serviriam tão somente para visibilizar e separar oponentes em uma disputa esportiva, assumindo mais uma vez e tão somente a função meramente representacional, explicitando uma função simbólica e moral de separar comunidades de interesse em lados opostos. Como se a camisa pudesse servir-se da qualidade totêmica, portanto metafórica, de classificação.

Tomar as camisas como índice de agência dos desempenhos, assim como uma roupa ou um modelo que participou de um desfile, ganha outra dimensão nas esferas estéticas de influência no mundo da moda, é perceber que camisas, primeiro, são tecnologias (porque tecnologia é cultura) e, segundo, formam uma camada, espécie de segundo espírito acoplado ao corpo de quem as possui, multiplicando suas potencialidades e qualidades técnicas. Que garoto, ao vestir uma camisa alusiva ao seu time ou ao seu ídolo esportivo não passou 
a interpretar ou expandir seu universo de ações e relações a partir dessa magia cheia de intencionalidades que potencializa sua pessoa?

Portanto, nem exatamente um instrumento externo de maximização de competitividade, nem exatamente uma representação tomada como um signo separado de seu significante (dos coletivos aos quais elas se remetem) investida como metáfora de algo que lhe seja exterior.

As camisas de futebol ganham outras aproximações analógicas (diria que metonímicas) e estéticas que merecem ser ressaltadas, sobretudo se assumirmos que são artefatos que circulam entre o campo da moda e o da arte, campos estes que estão amparados no trinômio produção, consumo e distinção (BOURDIEU, 1979), perfazendo as exigências de um estilo de vida consumerista e ávido por signos de riqueza amparados na desigualdade, também somam valores mais intangíveis de domínio da cultura urbana e do experimentalismo contextual. Nesse sentido, a moda esportiva futebolística detém características específicas ao tensionar as origens populares do futebol e os desdobramentos históricos que a transformaram em uma atividade profissional produtora de riqueza e poder.

Por isso, outras metaforizações podem servir como contraponto ou provocação em relação às mencionadas acima e que estão muito presentes no próprio imaginário torcedor, extrapoladas inclusive para o campo literário, tal como pode ser observado nas crônicas esportivas do dramaturgo Nelson Rodrigues. Ali, o cronista reintroduz a ideia generalizada de que uma camisa de futebol pode ter "alma”, "peso" ou, mais precisamente, vontade própria e agência:

Mas quando joga, o Flamengo tem, além de futebol, um outro valor mais alto. Refiro-me à camisa que não é, como querem alguns, demagogia sórdida. Não. E não creio que exista, no futebol brasileiro [1958], algo de tão ativo, militante, imbatível, como a camisa rubro-negro. (RODRIGUES, 1994, p. 40)

E finaliza a crônica com mais um de seus jogos de alusões hiperbolizadas que o notabilizaram no cenário literário e esportivo:

Então, diante de todos, o vice-campeão paulista [num jogo contra o time do Santos] tombou como um César apunhalado. Simples razões técnicas e táticas não explicam a reação furiosa. Eis por que o meu personagem da semana é, desta vez, uma camisa. (RODRIGUES, 1994, p. 40) 


\section{Arremate}

Em uma banca da qual participava como membro avaliador de uma tese de doutorado em História Econômica ${ }^{18}$, cujo tema do candidato era a profissionalização do futebol sob o ponto de vista de dois segmentos urbanos que desde muito precocemente se engajaram no futebol, os portugueses e os negros na cidade do Rio de Janeiro, pude tecer um comentário a respeito de como o pesquisador abordou a inserção das mulheres nesse universo, tomando como mote, em um dos tópicos da tese, justamente a moda feminina.

Acabei destacando esse tema na arguição que fiz ao seu texto e tentei ampliar essa discussão. Reproduzo o fragmento da defesa, posteriormente publicado em um livro dedicado às arguições:

Outro ponto importante é que a tese mostra como o futebol vai se masculinizando, decisões de ordem econômica, por exemplo extinguir a gratuidade que abarcava as mulheres e as famílias (não pagantes), com isso individualizando o processo de arregimentação da paixão, contribuindo decisivamente para essa masculinização, que impressiona sobretudo porque você também mostra que paradoxalmente "torcida" fez parte de um feixe de gestualidades muito femininas, ou seja, torcida era geralmente associada aos maneirismos corporais femininos em frenesi pelo jogo: "a palavra torcida estava disseminada nos estádios brasileiros e não eram só as fitas amarradas na roupa a imitar Marcos de Mendonça [famoso jogador da época e que cultivava uma moda toda pessoal] as únicas peças a serem retorcidas pelo público feminino. Seus vestidos, blusas e outras peças do vestuário eram torcidas durante o jogo (p. 87)”. Isso tudo vai ficando sério (no sentido que Huizinga atribui ao termo $)^{19}$, masculino, quantitativista, gerador de receitas e atraindo cada vez mais os interesses econômicos ao redor do jogo: “A necessidade de aumentar as arrecadações fazia com que os clubes, aos poucos e em ocasiões especiais, abandonassem o costume de sócios não pagarem ingressos e ainda serem acompanhados por suas mulheres e famílias, também isentas de pagamento" (p. 167 e 168). (TOLEDO, 2019, p. 197)

Este longo excerto revela, uma vez mais, a relação estreita e entrelaçada ao longo da história entre futebol e moda. Cumpre destacar o caráter inventivo, intencional, poético e agentivo no modo como as mulheres torciam e colocavam em cena sua corporalidade, ainda que paulatinamente fossem alijadas da sociabilidade esportiva, retomada as duras penas durante as décadas subsequentes.

\footnotetext{
${ }^{18}$ Tese de doutorado de João Casquinha Malaia Santos (2010).

${ }^{19}$ Homo Zudens, de Johan Huizinga, é um marco bibliográfico nos estudos sobre ludicidade. 4. ed. São Paulo: Perspectiva, 1993.
} 
0 caráter político subjacente à moda, presente nos estádios a serviço da crítica à desigualdade feita não sob os auspícios da razão pragmática, mas pela intencionalidade dos corpos e da agência das roupas, remete mais uma vez às noções sobre o estatuto desses artefatos (no caso, as indumentárias), que, na relação simbiótica com aquelas mulheres, produziram um comportamento peculiar, mais tarde definido genericamente por comportamento torcedor.

A singularização de uma ideia hegemônica de masculino entre torcedores e torcedoras escondeu os andaimes que legitimaram a noção genérica de torcida como um dos elementos importantes dos espetáculos futebolísticos. Andaimes feitos também por corpos femininos e o modo como as mulheres anônimas inventaram moda nos estádios.

Se, atualmente, a correlação entre esportes e moda esportiva parece demasiado óbvia, na qual mães, pais e adultos em geral mimetizam e consomem estilos jovens presentes nos corpos de seus filhos (estilo muito orientado por uma espessa e quase onipresente moda esportiva), não devemos escamotear que essa circularidade e esses fluxos contínuos obedeceram a um conjunto de relações cujos inputs individuais de pequenas, mas multiplicadas, ações aqui e acolá, tal como dessas mulheres presentes no alvorecer da prática futebolística no início do século XX, fizeram e fazem continuadamente do sistema da moda um vetor de simbolização dos mais importantes e cruciais para se experienciar a vida urbana como moda ou modalidade da cultura em seu sentido mais amplo, ou seja, como busca incessante pela pessoa.

O futebol feminino aí em pauta acaba apontando também para o quanto esse domínio esportivo pode ensinar para outros universos contíguos. Penso que a moda, em um sentido específico, como indutora de experimentalismos é um caso comparativo revelador. 0 jogo de espelhamentos entre gêneros, cuja função catártica aparece muito no domínio da moda, serve igualmente de promessa de que percepções mais igualitaristas podem ser compartilhadas.

[...] para continuarmos a repetir que "futebol é coisa de homem" é necessário especificar qual tipo de homem estamos falando, pois se quisermos questionar essa máxima é necessário lançar novas perspectivas e olhares em torno do nosso conceito de masculinidade na tentativa de compreendê-la como uma dimensão menos homogênea do que costumamos supor. 0 aumento da participação feminina no universo futebolístico tem sido importante, por contradizer noções de feminilidade ainda predominantes e culturalmente aceitas como ideais. Do mesmo modo que Virginia Woolf questionou uma série de verdades que giravam em torno da mulher, é igualmente importante fazer o mesmo em relação aos homens. (COSTA, 2007, p. 23)

Quase como uma metáfora kaxinawa (LAGROU, 2007), temos a possibilidade de pensar a forma das coisas - concepção tão cara à moda e aos esportes em geral - como agente não inerte e, portanto, estabelecer com o mundo outros regimes de intencionalidade para transformá-lo ou transfigurá-lo sem necessariamente esperarmos pelas grandes transformações econômicas e culturais que nos assombram. 


\section{Referências}

BERMAN, Marshal. Tudo que é sólido desmancha no ar: a aventura da modernidade. São Paulo: Companhia das Letras, 1986.

BOURDIEU, Pierre. La distinction: critique sociale du jugement. Paris: Minuit, 1979.

CIDREIRA, Renata Pitombo. Os sentidos da moda. São Paulo: Annablume, 2005.

Costa, Leda Maria. 0 que é uma torcedora? Notas sobre a representação e auto-representação do público feminino de futebol. Esporte e Sociedade, n. 4, ano 2, nov. 2006/fev. 2007.

DOSSIÊ FUTEBOL. Revista USP. São Paulo, Universidade de São Paulo, set./out./nov. 2013.

DOSSIÊ MEGAEVENTOS. Horizontes Antropológicos. Programa de Pós-Graduação em Antropologia Social - UFRGS, Porto Alegre, n. 40, ano 19, jul./dez. 2013.

FRANCISCON, Mário. Futebol: regras e legislação. 12. ed. São Paulo: Prol Ed. Gráfica Ltda., 1996.

FREHSE, Fraya. Roupas femininas: de missas, visitas e festas. In: Ô da rua!: o transeunte e o advento da modernidade em São Paulo. São Paulo: Edusp, 2011.

GUMBRECHT, Hans Ulrich. Instrumentos. In: . Elogio da beleza atlética. São Paulo: Companhia das Letras, 2005.

HUIZINGA, Johan. Homo ludens. São Paulo: Perspectiva, 1993.

Lagrou, Else. A fluidez da forma: arte, alteridade e agência em uma sociedade amazônica (Kaxinawa, Acre). Rio de Janeiro: TopBooks, 2007.

LEVI, Tatiana. Um dia, uma camisa. In: Luiz Rufato (Org.). Entre as quatro linhas. Contos sobre futebol. São Paulo: Ed. DSOP, 2013.

MASCARENHAS, Gilmar. Globalização e espetáculo: o Brasil dos megaeventos esportivos. In: Del Piori, Mary; Andrade de Melo, Victor. (Orgs.). História do esporte no Brasil. São Paulo: Editora Unesp, 2009.

MIZRAHI, Mylene. 0 funk, a roupa e o corpo: caminhos para uma abordagem antropológica da moda. Cadernos de Arte e Antropologia, v. 8, n. 1, 2019. Dossiê Moda: cultura material, modos de vestir e de se apresentar.

ROHDEN, Fabíola. A arte de enganar a natureza: contracepção, aborto e infanticídio no início do século XIX. Coleção história e saúde. Rio de Janeiro: Editora Fiocruz, 2013. 
RODRIGUES, Nelson. A camisa. In: A pátria de chuteiras: novas crônicas de futebol.

São Paulo: Companhia das Letras, 1994.

RODRIGUES FILHO, Nelson. Lima Barreto: jogando contra o futebol. Pesquisa de Campo. Revista do núcleo de Sociologia do Futebol - UERJ. Rio de Janeiro, n. 1, p. 43-53, 1995.

SANTOS, João Casquinha Malaia. Revolução vascaína: a profissionalização do futebol e a inserção socioeconômica de negros e portugueses na cidade do Rio de Janeiro (1915-1934). 489 folhas. Tese (Doutorado em História Econômica) - História, Universidade de São Paulo (USP), São Paulo, 2010.

SEVCENKO, Nicolau. Orfeu extático na metrópole. São Paulo: Companhia das Letras, 1992. SPAGGIARI, Enrico; MACHADO, Giancarlo; GIGLIO, Sérgio (Orgs.). Entre jogos e copas: reflexões de uma década esportiva. São Paulo: Fapesp, Intermeios, 2016.

Toledo, Luiz Henrique. Remexer anotações: o trabalho de um arguidor antropólogo. Coleção Aracy Lopes da Silva. Estudos de Antropologia Social. São Carlos: Edufscar, 2019.

TOLEDO, Luiz Henrique. De olhos bem abertos ou o que se viu e ouviu na Copa do Mundo de 2014: ensaio de antropologia das emoções esportivas. In: SPAGGIARI, Enrico; MACHADO, Giancarlo; GIGLIO, Sérgio (Orgs.). Entre jogos e copas: reflexões de uma década esportiva. São Paulo: Fapesp, Intermeios, 2016. p. 33-53.

TOLEDO, Luiz Henrique. Torcedores e o mercado de bens simbólicos. In: CAMPOS, Flávio; ALFONSI, Daniela (Orgs). Futebol objeto das Ciências Humanas. São Paulo: Leya, 2014.

TOLEDO, Luiz Henrique. Políticas da corporalidade: socialidade torcedora entre 1990-2010. In: TOLEDO, Luiz Henrique; MALAIA, João; BUARQUE DE HOLANDA, Bernardo; ANDRADE DE MELO, Victor (Orgs.). A torcida brasileira. Rio de Janeiro: Sete Letras, 2012.

TOLEDO, Luiz Henrique. Contribuições ao estudo da crônica esportiva 1: 'contracrônica' esportiva de Lima Barreto. Pesquisa de Campo. Revista do núcleo de Sociologia do Futebol - UERJ. Rio de Janeiro, n. 3/4, p. 35-50, 1996.

VEBLEN, Throstein B. A teoria da classe ociosa: um estudo econômico das instituições. São Paulo: Abril Cultural, 1983.

WAIZBORT, Leopoldo. As aventuras de Georg Simmel. 3. ed. São Paulo: Editora 34, 2013.

\section{Agradecimentos}

Agradeço ao antropólogo Wagner Xavier de Camargo as leituras prévias e a final deste texto, bem como a revisão do mesmo e a sua adequação ao formato da revista. 